\title{
Um Caso Raro de Dentes Neonatais
}

\author{
A Rare Case of Neonatal Teeth
}

\author{
Andreia A. MARTINS ${ }^{1}$, Cláudia FERRAZ1 ${ }^{1}$ Rute VAZ1 \\ Acta Med Port 2015 Nov-Dec;28(6):773-775
}

\section{RESUMO}

Os dentes neonatais correspondem a um distúrbio raro da erupção dentária, surgindo na cavidade oral no primeiro mês de vida, habitualmente na região anterior da mandíbula, sendo a sua etiologia desconhecida. Podem motivar dificuldades na amamentação e ser alvo de aspiração ou deglutição. Descreve-se o caso de um recém-nascido prematuro que no segundo dia de vida apresentava edema, hiperemia gengival e uma pequena tumefação na região dos incisivos centrais inferiores. Dez dias depois, foram detetados, nesse local, dois pequenos dentes com hipermobilidade, pelo que se procedeu a exodontia. Com este caso clínico pretende-se salientar a raridade dos dentes neonatais, sobretudo em recém-nascidos prematuros, a sua possível associação a várias síndromes e a necessidade de uma abordagem multifatorial na decisão terapêutica (exodontia/tratamento conservador).

Palavras-chave: Dentes Natais; Língua/lesões; Prematuro; Recém-Nascido; Úlceras Orais.

\section{ABSTRACT}

Neonatal teeth is a rare disorder of tooth eruption, arising in the oral cavity, usually in the anterior mandible, in the first month of life. Its etiology is unknown. This condition can cause breastfeeding difficulties, besides aspiration or swallowing of the teeth. We describe the case of a premature infant in the second day of life presented with gingival edema, redness and discrete swelling in the region of the mandibular central incisors. Ten days later, two small teeth with hypermobility were detected. Extraction of those teeth was performed. With this clinical case we intend to show the rarity of this entity, especially in premature infants, the possible association with various syndromes and the need for a multifactorial approach to the treatment decision (extraction / conservative treatment).

Keywords: Infant, Newborn; Infant, Premature; Natal Teeth; Oral Ulcer; Tongue/injuries.

\section{INTRODUÇÃO}

A erupção dentária é um processo fisiológico que se inicia, em média, aos seis meses de vida, com o aparecimento dos incisivos centrais inferiores decíduos. ${ }^{1}$ Porém, existem casos descritos na literatura de recém-nascidos (RN) que apresentam, ao nascimento ou durante o primeiro mês de vida, elementos dentários parcial ou completamente erupcionados, denominados dentes natais e neonatais, respetivamente. ${ }^{2}$ A sua etiologia permanece desconhecida, podendo estar associados a várias síndromes. ${ }^{1} \mathrm{~A}$ decisão terapêutica subordina-se a uma abordagem multifatorial, designadamente à dentição à qual o dente pertence, suas características e complicações. ${ }^{1}$

\section{CASO CLÍNICO}

RN do sexo feminino, gestação não vigiada, com serologias maternas periparto sem evidência de infeção ativa. Parto distócico por cesariana às 28 semanas (prematuridade espontânea), com peso ao nascimento de $1240 \mathrm{~g}$. No exame objetivo ao nascimento não apresentava dismorfias aparentes. Na primeira hora de vida foi internado na Unidade de Cuidados Intensivos Neonatais (UCIN) pela prematuridade e risco infecioso. No segundo dia de vida o RN apresentava edema e hiperemia do tecido gengival, na posição 71/81, associado a uma pequena tumefação local, sem outras alterações ao exame objetivo. Dez dias depois detetámos, nesse mesmo local, a presença de dois dentes de pequenas dimensões, amarelados e móveis (Fig. 1). Ao $15^{\circ}$ dia de vida constatámos a presença de uma úlcera na face interna do lábio inferior e hipermobilidade dentária. Atendendo à acentuada mobilidade e pouca inserção dentária, com consequente risco de aspiração, foi decidido, com a colaboração da Cirurgia Maxilo-Facial, realizar exodontia ao $16^{\circ}$ dia de vida (Fig. 2) na UCIN, que decorreu sem intercorrências.

É de destacar a existência de antecedentes familiares de dentes natais, em duas tias maternas, ambas $\mathrm{RN}$ de termo.

\section{DISCUSSÃO}

A prevalência dos dentes natais e neonatais oscila entre 1:2 $000-1: 3000$ dos $\mathrm{RN}^{1,{ }^{1,3}}$ encontrando-se descritos na literatura consultada dois casos de dentes neonatais e dois de dentes natais em RN prematuros, ${ }^{4-6}$ sendo a sua ocorrência nestes últimos ainda mais rara. $A$ incidência dos dentes natais revela-se superior à dos neonatais $(3: 1)^{1}$ surgindo, habitualmente, na região anterior da mandíbula, na posição dos incisivos centrais inferiores (85\%), tal como no caso clinico descrito.

A maioria dos dentes natais e neonatais representa a erupção precoce da dentição decídua normal, sendo

1. Serviço de Neonatologia. Hospital Pedro Hispano. Unidade Local de Saúde de Matosinhos. Matosinhos. Portugal.

$\triangle$ Autor correspondente: Andreia A. Martins. andreiaamartins87@gmail.com

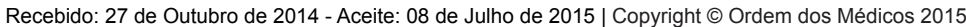




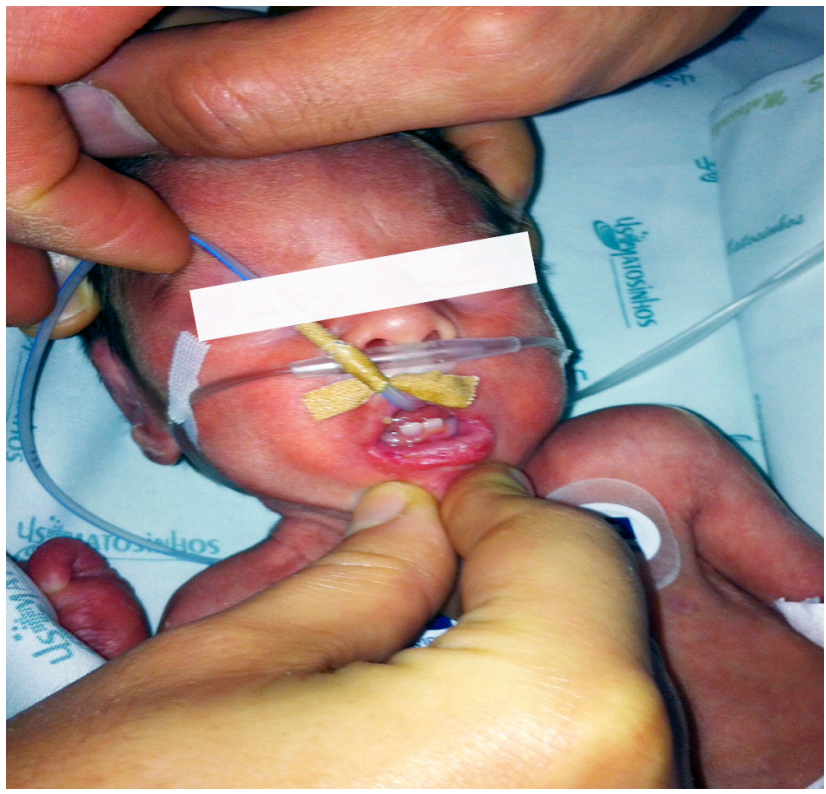

Figura 1 - Dentes neonatais na posição dos incisivos centrais inferiores, ao $12^{\circ}$ dia de vida

apenas menos de $10 \%$ supranumerários..$^{1,3}$ Muitos autores relatam uma predominância destes dentes no género feminino,,$^{3,7}$ no entanto é uma questão que permanece controversa. O RN do caso descrito era do sexo feminino, o que, segundo muitos autores, caracteriza o caso como clássico.

Apesar da sua etiologia não ser conhecida, este distúrbio da erupção dentária tem sido relacionado com a posição superficial do gérmen dentário, ${ }^{1,3,7}$ infeções ${ }^{1,3}$ (sífilis congénita), ${ }^{1}$ distúrbios endócrinos (hiperplasia congénita da supra renal $)^{8}$ e hereditariedade. ${ }^{1}$ Pode também estar associado a síndromes ${ }^{1,7}$ como displasia ectodérmica, síndrome de Pierre Robin, síndrome de Ellis-Van Creveld, síndrome de Turner, síndrome de Noonan, síndrome de Soto e disostose craniofacial. No presente caso, atendendo aos antecedentes familiares, a hipótese de hereditariedade tem que ser colocada, não se excluindo a hipótese sindromática, uma vez que se trata de um RN que poderá ainda não apresentar estigmas sindrómicos.

Clinicamente, este tipo de dentes podem apresentar-se com tamanho e forma normais. Porém, na maioria dos casos, são pequenos, cónicos, de coloração amarelada, com hipoplasia de esmalte e desenvolvimento radicular deficiente ou ausente. ${ }^{1,8}$ Devido a este desenvolvimento radicular apresentam grande mobilidade, tal como no caso descrito, podendo causar dor e desconforto durante a amamentação, ${ }^{9}$ bem como ser alvo de deglutição ou aspiração. ${ }^{1,3,9}$ Atendendo aos seus bordos cortantes e pontiagudos, ${ }^{1,3,7}$ a ulceração traumática na porção ventral da língua, conhecida como doença de Riga-Fede, ${ }^{10}$ é a complicação associada mais comum. Neste caso, porém, o RN apresentava uma lesão traumática numa localização menos comum face interna do lábio inferior.

Os quistos epidérmicos gengivais fazem diagnóstico diferencial com os dentes neonatais, sendo a radiografia periapical de relevante importância para confirmação do

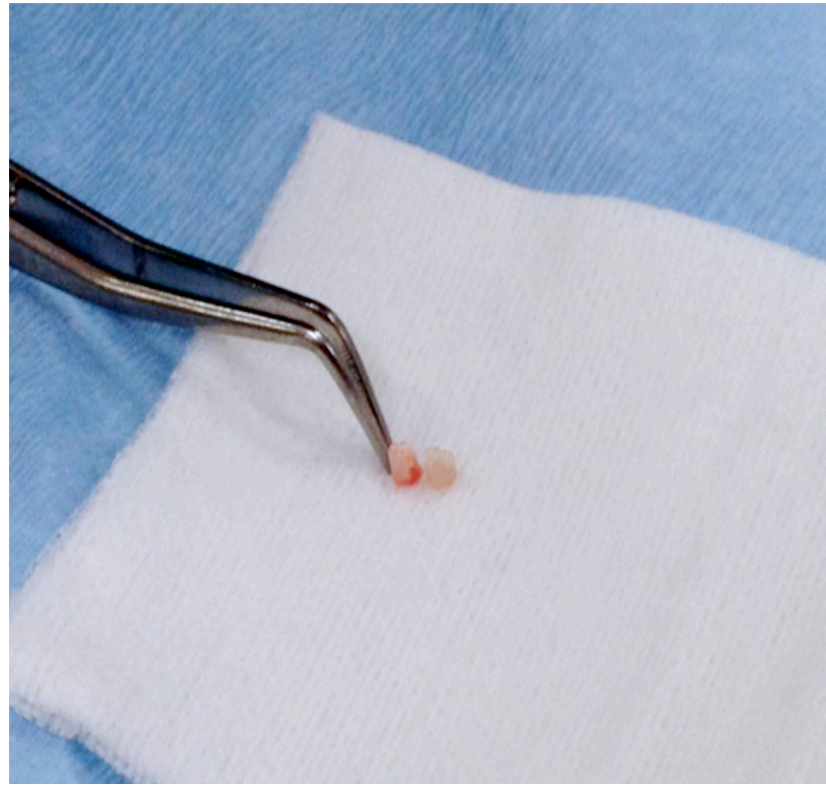

Figura 2 - Dentes neonatais (71 e 81) extraídos

diagnóstico. O estudo radiológico é também utilizado para averiguar a dentição à qual o dente pertence e avaliar o seu grau de desenvolvimento radicular. ${ }^{1}$

O estabelecimento de um plano de tratamento (conservador/cirúrgico) é um desafio, devendo a decisão ser tomada por um Pediatra e um profissional especializado (Estomatologia / Cirurgia Maxilo-Facial / Odontopediatria), tendo em consideração alguns factores, tais como o grau de implantação e a mobilidade dentária, interferência com a amamentação, existência de lesão traumática e a dentição à qual o dente pertence (dentição decídua normal ou dente supranumerário). 1,3,7,9 Quando o dente pertence à dentição decídua normal, a sua manutenção na cavidade oral é de extrema importância a fim de evitar perda de espaço e colapso no desenvolvimento da arcada dentária, com consequente má oclusão na dentição permanente ${ }^{1,9}$ e possíveis complicações que lhe são adjacentes - estéticas, fonéticas e mastigatórias. ${ }^{11} \mathrm{~A}$ exodontia precoce pode ainda retardar a erupção dos dentes permanentes sucessores. ${ }^{8}$ Porém, se o dente apresentar elevado grau de mobilidade com risco de deglutição ou aspiração e, ainda, interferir com a amamentação, deve proceder-se à sua exodontia (tratamento cirúrgico). ${ }^{1}$ De ressalvar que, para muitos autores, a presença de úlcera na posição ventral da língua, por si só, não é indicação para extração do dente, podendo optar-se pelo alisamento dos bordos incisais (tratamento conservador). ${ }^{3,6} \mathrm{Na}$ presença de um dente supranumerário, a exodontia é recomendada. ${ }^{8}$ No presente caso, não havendo dúvidas quanto ao diagnóstico e atendendo à acentuada mobilidade dentária (com consequente risco de aspiração/ deglutição), decidimos realizar exodontia sem radiografia prévia, dado que, independentemente da dentição à qual estes dentes pertencessem, a decisão terapêutica seria a mesma, evitando-se, deste modo, submeter o $\mathrm{RN}$ a radiação. Atendendo à possibilidade de se tratar de dentes 
decíduos e às consequências da sua extração precoce, este RN deverá ser acompanhado por Odontopediatria.

A exodontia deve ser evitada durante os primeiros dez dias de vida do $\mathrm{RN}$, devido à incapacidade de produção de vitamina $\mathrm{K}$, necessária ao processo hemostático..$^{3,7}$ Encontrando-se o RN no $16^{\circ}$ dia de vida, procedeu-se a exodontia com segurança, com a colaboração da Cirurgia Maxilo-Facial.

Dada a raridade deste distúrbio, ressalva-se a importância deste caso, que representa, segundo a literatura consultada, o terceiro caso a ser reportado de dente neonatal em RN prematuro. O conhecimento dos Pediatras sobre este distúrbio de erupção dentária é fulcral, contribuindo para uma correta e precoce intervenção.

\section{PROTECÇÃO DE PESSOAS E ANIMAIS}

Os autores declaram que os procedimentos seguidos estavam de acordo com os regulamentos estabelecidos pelos responsáveis da Comissão de Investigação Clínica e Ética e de acordo com a Declaração de Helsínquia da Associação Médica Mundial.

\section{CONFIDENCIALIDADE DOS DADOS}

Os autores declaram ter seguido os protocolos do seu centro de trabalho acerca da publicação dos dados de doentes.

\section{CONFLITOS DE INTERESSE}

Não existem conflitos de interesse a declarar.

\section{FONTES DE FINANCIAMENTO}

Não foi recebido qualquer subsídio ou bolsa.

\section{REFERÊNCIAS}

1. Diniz MB, Gondim JO, Pansani CA, Abreu e Lima FC. A importância da interação entre odontopediatrias e pediatrias no manejo de dentes natais e neonatais. Rev Paul Pediatr. 2008;26:64-9.

2. Adekoya-Sofovora CA. Natal and neonatal teeth: a review. Niger Postgrad Med J. 2008;15:38-41.

3. Leung AK, Robson WR. Natal teeth: a review. J Natl Med Assoc. 2006;98:226-8.

4. Cizmeci MN, Kanburoglu MK, Uzun FK, Tatli MM. Neonatal tooth in a preterm infant. Eur J Pediatric. 2013;172:279.

5. Sureshkumar R, McAulay AH. Natal and neonatal teeth. Arch Dis Child Fetal Neonatal. 2002;87:F227.

6. El Khatib K, Abouchadi A, Nassih M, Rzin A, Jidal B, Danino A, et al.
Dents natales: à propos de cinq cas. Rev Stomatol Chir Maxillofac. 2005;106:325-7.

7. Sevalho ML, Hanan SA, Filho AO, Medina PO. Dentes natais - relato de caso clínico. ConScientiae Saúde. 2011;10:160-5.

8. Barbosa RC, Corrêa MS, Lopes LD. Dente neonatal: relato de caso clínico. Rev Inst Cienc Saúde. 2008;26:130-4.

9. Cunha RF, Boer FA, Torriani DD, Frossard WT. Natal and neonatal teeth: review of literature. Pediatric Dent. 2001;23:158-62.

10. Jariwala D, Graham RM, Lewis T. Riga-Fede disease. $\mathrm{Br}$ Dent J. 2008;204:171.

11. Pinho T. A ortodontia interativa nas deformidades dento-maxilares. Nascer Crescer. 2011;20:192-6. 


\section{Um Caso Raro de Dentes Neonatais}

Acta Med Port 2015:28:773-775

Publicado pela Acta Médica Portuguesa, a Revista Científica da Ordem dos Médicos

Av. Almirante Gago Coutinho, 151

1749-084 Lisboa, Portugal.

Tel: +351218428 215

E-mail: submissao@actamedicaportuguesa.com

www.actamedicaportuguesa.com

ISSN:0870-399X | e-ISSN: 1646-0758

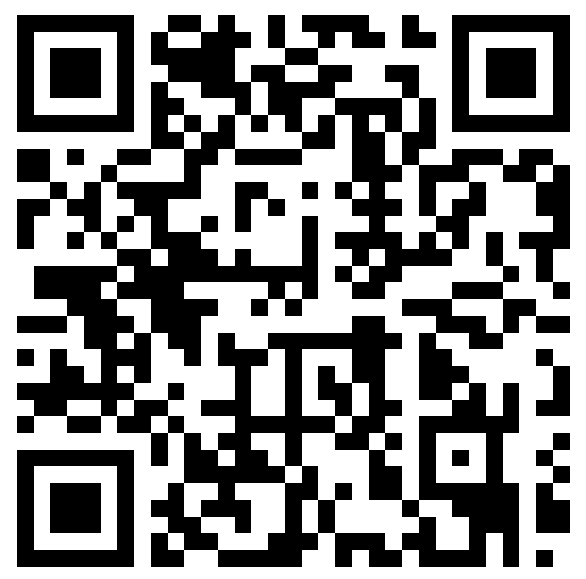

